\title{
Low Rectal Cancers: Evolution from Abdominoperineal Resection (APR) to Sphincter Saving Procedures (SSP)
}

\author{
Asif Mehraj* \\ Department of Colorectal Surgery, Sher-I-Kashmir Institute of Medical Sciences, India
}

Submission: January 19, 2018; Published: August 27, 2018

*Corresponding author: Asif Mehraj, Department of Colorectal Surgery, Sher-I-Kashmir Institute of Medical Sciences, Srinagar, Jammu \& Kashmir, India; Email: asifdr80@yahoo.co.in

Abstract

Background: Distal rectal cancers present a challenging task for surgeons in terms of providing a Sphincter Saving Procedure (SSP) as compared to Abdominal Perineal Resection (APR) and maintaining oncological safety. APR used to be commonly performed surgery for distal rectal cancers, but because of better understanding of cancer biology, better surgical techniques, newer neoadjuvant therapies \& advent of surgical staplers, SSP are being preferred by both surgeons \& patients. Primary aim of our study was to determine the various types of surgical treatment options in practice for distal rectal tumours \& to compare the trend of Abdominal perineal resection and Sphincter saving procedures in a high-volume centre.

Methods: It was a retrospective study of 3 years, carried out a high volume colorectal surgery division at a tertiary care institute. Patients with cancers \& precancerous lesions within $10 \mathrm{~cm}$ from anal verge who underwent APR \& other SSP were included. Data was collected retrospectively from patient case sheets, medical record section, operation theatre registry and outpatient department follow up register and tabulated and processed in Microsoft excel.

Results: Overall incidence of APR as compared to SSP was $17.36 \%$. In lesions $\leq 6 \mathrm{~cm} \& \leq 7.5 \mathrm{~cm}$ APR constituted $26.4 \% \& 22.7 \%$ respectively. Low Anterior resection including Ultra Low Anterior Resection was the most commonly performed operation (101 patients). Trans anal excision including Transanal Minimally Invasive Surgery (TAMIS) was performed in 37 patients.

Conclusion: As a result of improved surgical skills, better technology and high volume centre the trend is shifting more towards sphincter saving procedures.

Keywords: Colorectal surgery; Sphincter; Abdominal perineal; Trans anal excision

Abbreviations: SSP: Sphincter Saving Procedure; APR: Abdominal Perineal Resection; LAR: Low Anterior Resection; TAE: Transanal Excision; TAMIS: Transanal Minimal Invasive Surgery; TEMS: Transanal Endoscopic Microsurgery; ISR: Intersphincteric Resections; TATA: Transanal Transabdominal

\section{Introduction}

Management of low rectal tumours is challenging for the surgeon as well as the patient as it involves subjecting the patient to a temporary, permanent or no stoma without compromising oncologic safety. Technically working in the confines of deep pelvis is a daunting task for achieving these results. The decision whether to leave a patient with a permanent stoma or save his sphincter is of utmost importance. Surgery for low rectal cancer has gradually evolved towards more sphincter saving procedures (SSP), mainly as a result of

a) Better understanding of cancer biology

b) Improved surgical techniques c) Neo adjuvant therapy

d) Use of surgical staplers.

e) Limited distal margin,1-2 $\mathrm{cm}$ instead of $5 \mathrm{~cm}$

f) Concept of coloanal anastamosis (TATA Surgery)

With the advent of advanced gadgets and better understanding of tumour characteristics, more and more patients are subjected to SSP instead of APR.

The importance of distal resection margin is being overshadowed by circumferential resection margin. The main limit for sphincter preservation is not the longitudinal distance between the tumour and the anal sphincter, but the 
circumferential distance between the tumour and the skeletal muscles of the pelvic floor. This new concept transforms a $1 \mathrm{~cm}$ discussion to a $1 \mathrm{~mm}[1]$.

Low anterior resection (LAR) is the most commonly performed SSP in distal rectal tumours, besides other options like various forms of Transanal Excision (TAE), transanal minimal invasive surgery (TAMIS), transanal endoscopic microsurgery (TEMS), intersphincteric resections (ISR) and other hybrid procedures like transanal transabdominal (TATA) surgeries. Most studies have reported an APR to LAR ratio of $1: 3$ or $1: 4$, suggesting that LAR may be oncologically superior to APR [2-4].

Depending of the experience of the surgeon and specialization of the hospital, the rate of APR in rectal cancer surgery varies from $8 \%$ to $53 \%$ [5].

\section{Objectives}

Primary outcome measure of our study was to determine the various types of surgical treatment options in practice for distal rectal tumours \& to compare the trend of APR and SSP in a highvolume centre.

\section{Patients \& Methods}

This is a retrospective study of 3 years (2014-2016), carried out in the Colorectal Division of Department of General \& Minimal Access Surgery SKIMS, Srinagar, India, which is a tertiary care institute \& a high volume centre for colorectal surgery. Institute approval was sought to collect the data for publication purpose. Data was collected from Operation theatre record register, Medical Record Department, Pathology Department Archives Store and OPD follow up register. Documented carcinoma rectum $<10 \mathrm{~cm}$ from $\mathrm{AV}$, patients who have underwent $A P R$ and LAR as recorded in case sheets \& patients of various types of adenomas in low and middle rectum were included in the study. Patients undergoing Anterior resections, simultaneous surgical procedures, unresectable tumours at laparotomy \& excision done for other benign pathologies were excluded from the study. We allocated patients to two groups:

i. Group A including patients who underwent APR

ii. Group B including patients who underwent various types of SSP like LAR, TAE \& TAMIS.

All the data was collected \& tabulated in Excel work sheet. Statistical analysis of data was done using Microsoft Excel and SPSS software.

\section{Results}

Table 1: Age distribution.

\begin{tabular}{|c|c|c|}
\hline Age (years) & Frequency & Percentage \\
\hline$<30$ & 18 & 10.8 \\
\hline $30-39$ & 26 & 15.6 \\
\hline $40-49$ & 36 & 21.6 \\
\hline $50-59$ & 34 & 20.4 \\
\hline $60-69$ & 39 & 23.4 \\
\hline$>70$ & 14 & 8.4 \\
\hline
\end{tabular}

Data of 167 patients was included in the study. More than 50 $\%$ of patients were above 50 years of age and almost $25 \%$ were younger than 40 years. Mean $( \pm S D)$ age was $46.1( \pm 7.89)$ years (Table 1).

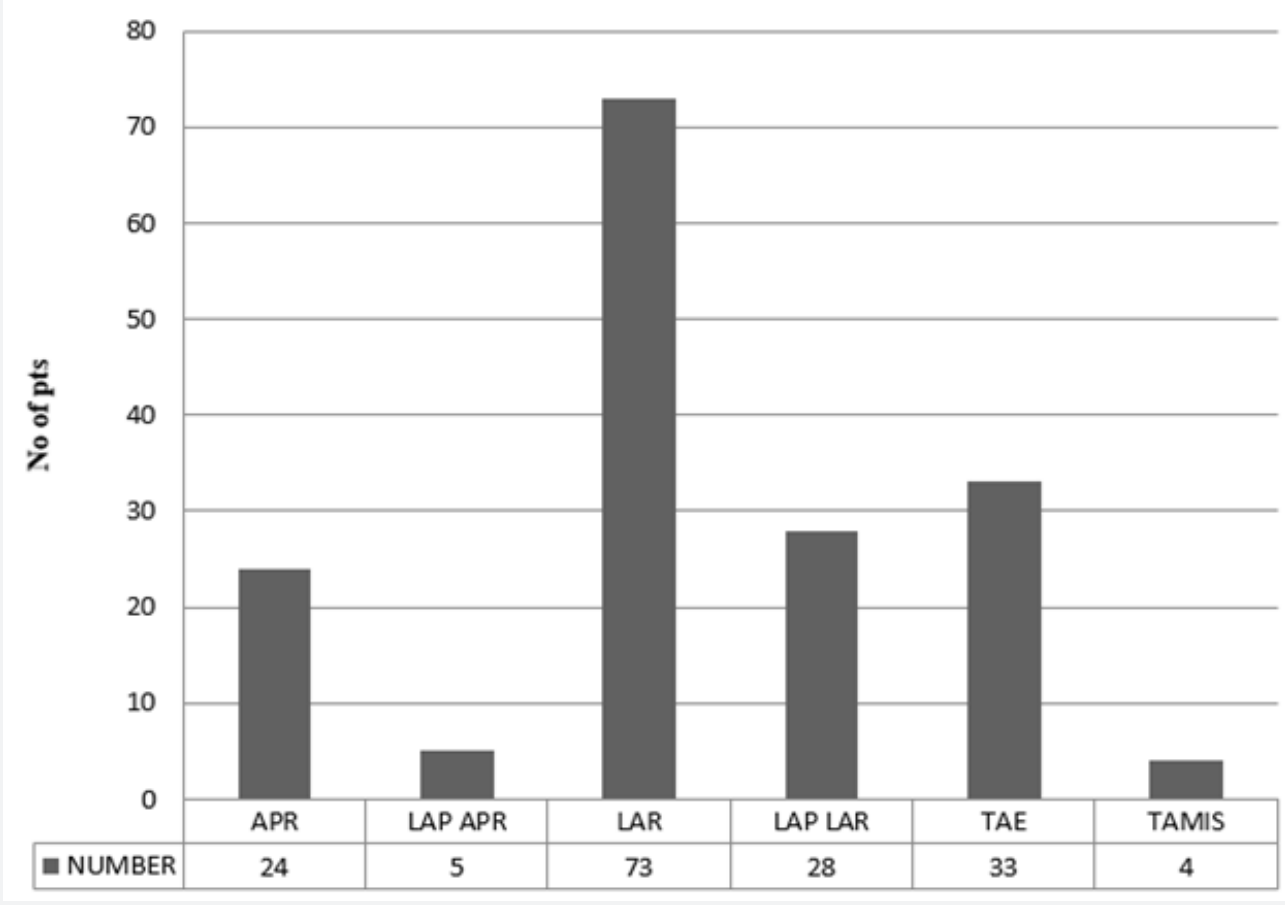

Figure 1: Surgical procedure. 
Surgical operations performed included 29 APR's, 101 LAR's and 37 local excisions (LE) Figure 1.

Table 2: Age \& gender distribution.

\begin{tabular}{|c|c|c|c|c|}
\hline \multicolumn{2}{|c|}{ Parameter } & Group A & Group B & P Value \\
\hline \multicolumn{2}{|c|}{ Mean Age (Years) } & 52.03 & 48.51 & 0.236 \\
\hline Gender & Male & $16(55.2 \%)$ & $66(47.8 \%)$ & 0.472 \\
\hline & Female & $13(44.8 \%)$ & $72(52.2 \%)$ & \\
\hline
\end{tabular}

The two groups were comparable in terms of age \& gender. (Table 2).

Table 3: APR Vs SSP.

\begin{tabular}{|c|c|c|c|}
\hline \multirow{2}{*}{ Overall } & & Frequency & Percentage \\
\hline \multirow{3}{*}{$\leq 6 \mathrm{CM}$} & Group A & 29 & 17.36 \\
\cline { 2 - 4 } & Group B & 138 & 82.64 \\
\hline \multirow{2}{*}{$\leq 7.5 \mathrm{CM}$} & Group A & 29 & 26.4 \\
\cline { 2 - 4 } & Group B & 81 & 73.6 \\
\cline { 2 - 4 } & Group A & 29 & 22.7 \\
\hline
\end{tabular}

Out of 167 total patients, 143 were operated for rectal adenocarcinoma and 24 for adenomas with high grade dysplasia. APR was performed in 29 (17.36\%), LAR in 101 (60.48\%) and LE in $37(22.16 \%)$ patients, hence SSP in 138 (82.64\%). In case of cancer rectum only i.e. 143 patients, 29 (20.28) were subjected to APR \& 114 (79.72\%) were subjected to SSP (LAR+LE). We further did subgroup analysis of patients whose growths were within $6 \mathrm{~cm} \& 7.5 \mathrm{~cm}$ from anal verge. Rate of APR was 26.4 and $22.7 \%$ respectively (Table 3 ). In further sub group analysis, we compared the rate of APR vs. LAR in patients with growths within $6 \mathrm{~cm} \& 7.5 \mathrm{~cm}$ and the rate of APR was 35.8 and $29.6 \%$ respectively (Table 4).

Table 4: APR Vs LAR.

\begin{tabular}{|c|c|c|c|}
\hline & & Frequency & Percentage \\
\hline \multirow{2}{*}{$\leq 6 \mathrm{CM}$} & APR & 29 & 35.8 \\
\cline { 2 - 4 } & LAR & 52 & 64.2 \\
\hline \multirow{3}{*}{$\leq 7.5 \mathrm{CM}$} & APR & 29 & 29.6 \\
\cline { 2 - 4 } & LAR & 69 & 71.4 \\
\hline
\end{tabular}

\section{Discussion}

The standard approach of curative treatment in rectal cancer is surgery. Early stage cancers may be successfully treated with local excision. However, the vast majority of rectal cancers present at advanced stages and need more extensive surgery in the form of LAR or APR. Treatment of distal rectal tumours is challenging in providing a continent anal opening. Sphincter preservation with coloanal anastomosis in LAR has become an established option for low rectal cancers, however most patients with rectal cancer involving anal canal are routinely treated with APR.

Colorectal cancer generally tends to be more common in elderly, but the incidence among younger patients is increasing.
Both the incidence and mortality rates of CRC have been decreasing in the United States [6]. The observed decline in incidence is largely attributed to an increase in screening, specifically colonoscopy, which is recommended for all adults 50 years or older [7]. Conversely, the incidence of CRC in adults younger than 50 years, for whom CRC screening is not recommended, appears to be increasing, and these patients are more likely to present with advanced disease $[8,9]$.

Several individual studies from Indian subcontinent consistently document a relatively high proportion of young age rectal cancer, with a mean age of around 40-45 yr [10-12]. In our study proportion of patients younger than 40 years was $26.4 \%$ and mean age of presentation was 50.27 years.

In a retrospective study of 153 patients of rectal cancer involving lower and middle rectum, Shapour Omidvari et al reported that out of 138 patients subjected to surgery 96 (70\%) underwent LAR and $42(30 \%)$ were subjected to APR [13]. Thus LAR to APR ratio was close to 1:3. In our study the overall incidence of APR as compared to other sphincter saving procedures was $17.36 \%$ which is close to 1:6. In 2007 data from Tata Memorial Hospital, Mumbai, one of the largest centres catering to colorectal cancer surgeries in India (2005 data) revealed the rate of APR being $45 \%$ as compared to $55 \%$ for LAR in low rectal cancers [14]. If we look at some of the largest clinical trials in rectal surgery, the aggregate percentage of patients subjected to APR is $39 \%$ (Table 5) [15].

Table 5: Landmark rectal cancer surgery trials.

\begin{tabular}{|c|c|c|c|}
\hline Trial name & No of pts & APR Rate (\%) & NACRT \\
\hline NSABPR-03 & 116 & 67 & No \\
\cline { 2 - 4 } & 1168 & 55 & Yes (RT) \\
\hline $\begin{array}{c}\text { Swedish rectal cancer } \\
\text { trial }\end{array}$ & 2136 & 38 & - \\
\hline $\begin{array}{c}\text { Norwegian rectal } \\
\text { cancer trial }\end{array}$ & 1805 & 32 & - \\
\hline $\begin{array}{c}\text { Dutch colorectal } \\
\text { cancer trial }\end{array}$ & 4849 & 39 & - \\
\hline Aggregate & & & \\
\hline
\end{tabular}

In tumours located $\leq 6 \mathrm{~cm} 26.4 \%$ of patients underwent APR as compared to $73.6 \%$ who were subjected to various SSPs. At Cleveland Clinic (1995 to 2009) out of 153 low rectal cancer $(<5 \mathrm{~cm})$ patients, sixty-eight $(44 \%)$ underwent APR and 85 (56 $\%)$ patients underwent LAR. Five of the 85 LAR operations were inter sphincteric resections $(<5 \mathrm{~cm})[16]$.

Jonas Geohl from a cancer centre in Germany reported their data from1985 to 2007 (Table 6), wherein they performed surgeries on 725 low rectal cancers within $7.5 \mathrm{~cm}$ from anal verge. SSP were performed in 379 (52.3\%) patients including LAR in 275 and inter sphincteric resection in 104 patients. APR was done on $346(47.7 \%)$ patients [17]. In our series $29.6 \%$ patients who had their tumours within $7.5 \%$ were subjected to APR. 


\section{Advanced Research in Gastroenterology \& Hepatology}

Table 6: German cancer center data.

\begin{tabular}{|c|c|c|c|c|c|c|}
\hline & $1985-2007$ & 1985-1994 & P Value & $1995-2001$ & P Value & 2002-2007 \\
\hline $\mathrm{N}$ & 725 & 303 & & 205 & & 217 \\
\hline Sex & & & 0.035 & & 0.561 & \\
\hline Male & $487(67.2 \%)$ & $190(62.7 \%)$ & & $147(71.7 \%)$ & & $150(69.1 \%)$ \\
\hline Female & $238(32.8 \%)$ & $113(37.3 \%)$ & & $58(28.3 \%)$ & & $67(30.9 \%)$ \\
\hline Age (Years) & & & 0.499 & & 0.66 & \\
\hline Median (Range) & $62(21-92)$ & $61(21-85)$ & & $61(27-92)$ & & $62(22-87)$ \\
\hline Procedure & & & $<0.001$ & & $<0.001$ & \\
\hline LAR & 275 (37.9) & $100(33 \%)$ & & $58(28.3 \%)$ & & $117(53.9 \%)$ \\
\hline ISR & $104(14.3)$ & $10(3.3 \%)$ & & $55(26.8 \%)$ & & $39(18.0 \%)$ \\
\hline APR & $346(47.7)$ & $19(63.7 \%)$ & & $92(44.9 \%)$ & & $61(28.1 \%)$ \\
\hline
\end{tabular}

One of the reasons for a low rate of APR in our study is the volume of rectal surgeries we perform at our centre. On an average we perform more than 100 rectal cancer surgeries and along with colon almost 250-300 colorectal cancer surgeries every year. In this study we have included only low and middle rectal cancers over a period of 3 years and the number is 167 for 3 years. A high-volume centre has been defined as a centre where $>24$ (17-35) rectal cancer surgeries or $>126$ (85-167) colon surgeries are performed per year [18]. In a meta-analysis by Talya Salz et al. [19] they reported that many studies that measured hospital volume and surgery type, found a positive association between higher hospital volume and higher rate of sphincter-sparing procedures. The significant odds ratios were $0.44,0.55$, and 0.73 . Significant differences between APR rates for high and low volume hospitals were reported as $26.4 \%$ vs. $29.8 \%$ for high and low volume, respectively, in one study, and $47 \%$ vs. $49 \%$ for high and low volume hospitals, respectively, in another study $[20,21]$.

\section{Conclusion}

Low rectal cancer continues to be a challenge for the surgeon in maintaining balance between oncological clearance and sphincter preservation. Most of such patients can be offered continent sphincters as a result of improvement in knowledge and skills besides innovations in technology. The case volume of the centre plays a pivotal role in performing sphincter preserving operations. Ideally all low volume centres should preferably refer these cases to high volume centres for giving the maximum possible benefit to the patients in the form of sphincter preservation and better quality of life.

\section{References}

1. Taylor FG, Quirke P, Heald RJ, Moran B, Blomqvist L, et al. (2011) One millimeter is the safe cut-off for magnetic resonance imaging prediction of surgical margin status in rectal cancer. Br J Surg 98(6): 872-879.

2. Schoetz DJ Jr (2006) Evolving practice patterns in colon and rectal surgery. J Am Coll Surg 203(3): 322-327.

3. Perry WB, Connaughton JC (2007) Abdominoperineal resection: how is it done and what are the results? Clin Colon Rectal Surg 20(3): 213220
4. Nagtegaal ID, van de Velde CJ, Marijnen CA, van Krieken JH, Quirke $P$ (2005) Low rectal cancer: a call for a change of approach in abdominoperineal resection. J Clin Oncol 23(36): 9257-9264.

5. Morris E, Quirke P, Thomas JD, Fairley L, Cottier B, et al. (2008) Unacceptable variation in abdominoperineal excision rates for rectal cancer: time to intervene? Gut 57(12): 1690-1697.

6. Siegel R, Naishadham D, Jemal A (2013) Cancer statistics, 2013. CA Cancer J Clin 63(1): 11-30.

7. Edwards BK, Ward E, Kohler BA Eheman C, Zauber AG, et al. (2010) Annual report to the nation on the status of cancer, 1975-2006, featuring colorectal cancer trends and impact of interventions (risk factors, screening and treatment) to reduce future rates. Cancer 116(3): 544-573.

8. Siegel RL, Jemal A, Ward EM (2009) Increase in incidence of colorectal cancer among young men and women in the United States. Cancer Epidemiol Biomarkers Prev 18(6): 1695-1698.

9. You YN, Xing Y, Feig BW, Chang GJ, Cormier JN (2012) Young-onset colorectal cancer: is it time to pay attention? Arch Intern Med 172(3): 287-289.

10. Nath J, Wigley C, Keighley MR, Perakath B (2009) Rectal cancer in young adults: a series of 102 patients at a tertiary care centre in India. Colorectal Dis 11(5): 475-479.

11. Gupta S, Bhattacharya D, Acharya AN, Majumdar S, Ranjan P, et al. (2010) Colorectal carcinoma in young adults: a retrospective study on Indian patients: 2000-2008. Colorectal Dis 12(10): 182-189.

12. Ahmed S, Banerjea A, Hands RE, Bustin S, Dorudi S (2005) Microarray profiling of colorectal cancer in Bangladeshi patients. Colorectal Dis 7(6): 571-575.

13. Shapour Omidvari, Sayed Hassan Hamedi, Mohammad Mohammadiapannah, Samira Razzaghi, Ahmad Mosalaei, et al. (2013) Comparison of abdominoperineal resection and low anterior resection in lower and middle rectal cancer. J Egypt Natl Canc Inst 25(3): 151160.

14. Shailesh V Shrikhande, Rajesh R Saoji, Savio G Barreto, Anagha C Kakade, Stephen D Waterford, et al. Outcomes of resection for rectal cancer in India: The impact of the double stapling technique. World J Surg Oncol 2007 5: 35.

15. JH Marks, George J Nassif, Gerald Marks (2012) Transanal Abdominal Transanal proctosigmoidectomy with descending coloanal anastomosis (the TATA procedure) for low rectal cancer treated with chemoradiation. Intersphincteric resection for low tumors of the rectum, Vienna, Springer, pp. 153-156.

16. Kim JW (2011) Quality of life after rectal cancer surgery. Korean J Gastroenterol 47(4):295-299. 
17. Jonas Gohl, Werner Hohenberger, Susanne Merkel (2012) Inter sphincteric resection of low rectal tumors. Vienna, Springer.

18. W van Gijn, GA Gooiker, MWJM Wouters, PN Post, RAEM Tollenaar, et al. (2010) Volume and outcome in colorectal cancer surgery. Eur J Surg Oncol 36(1): S55-S63.

19. Talya Salz, Robert S Sandler (2008) The effect of hospital and surgeon volume on outcomes for rectal cancer surgery. Clin Gastroenterol
Hepatol 6(11): 1185-1193.

20. Marusch F, Koch A, Schmidt U, Pross M, Gastinger I, et al. (2001) Hospital caseload and the results achieved in patients with rectal cancer. Br J Surg 88(10): 1397-1402.

21. AJ Simons, R Ker, S Groshen, C Gee, GJ Anthone, et al. (1997) Variations in treatment of rectal cancer: the influence of hospital type and case load. Dis Colon Rectum 40(6): 641-646.

\section{Your next submission with JuniperPublishers will reach you the below assets}

- Quality Editorial service

- Swift Peer Review

- Reprints availability

- E-prints Service

- Manuscript Podcast for convenient understanding

- Global attainment for your research

- Manuscript accessibility in different formats

( Pdf, E-pub, Full Text, audio)

- Unceasing customer service

Track the below URL for one-step submission https://juniperpublishers.com/online-submission.php 